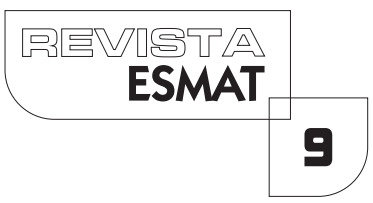

\title{
A VIOLAÇÃO DOS DIREITOS HUMANOS NO TOCANTINS CAUSADOS PELOS CRIMES DOLOSOS CONTRA A VIDA E A INVISIBILIDADE DA SUA TIPIFICAÇÃO POR CLASSE SOCIAL, POR QUESTÃO ÉTNICO-RACIAL E GÊNERO'
}

Cibele Maria Bellezzia

Mestranda em Prestação Jurisdicional e Direitos Humanos pela UFT. Juíza de Direito da Comarca de Peixe, Estado do Tocantins.E-mail: cibelebellezzia@yahoo.com.br

\section{Damião Rocha}

Doutor em Educação pela UFBA. Mestre em Educação pela UFG. Docente do Programa de Pós-Graduação Stricto Sensu em Educação (PPGE/UFT) e do Mestrado em Prestação Jurisdicional e Direitos Humanos da UFT. Docente Adjunto da UFT. Email:damiao@uft.edu.br

\section{RESUMO}

Os crimes dolosos contra a vida ferem o mais importante direito humano: a vida. Portanto, para que haja efetivamente punição, é necessário que o trâmite tanto na fase administrativa (inquérito policial) quanto na fase judicial (processo-crime) deva ser o mais célere possível, a fim de que seja dada uma resposta tanto para a família enlutada como para a sociedade, sem, contudo se descuidar do devido processo penal (contraditório, ampla defesa, provas lícitas, juiz natural, publicidade, imparcialidade, verdade real, igualdade das partes, paridade de armas, identidade física do juiz, favor rei). $\bigcirc$ trabalho resulta da pesquisa de Mestrado em Prestação Jurisdicional e Direitos Humanos em que elaboramos diagnóstico da prestação jurisdicional nas comarcas de Figueirópolis, Peixe e Gurupi ( I ${ }^{\mathrm{a}}, 2^{\mathrm{a}}$ e $3^{\mathrm{a}}$ Entrâncias, respectivamente), no período de 2002 a 2006 no estado do Tocantins. O OBJETIVO foi diagnosticar a efetividade da prestação jurisdicional nas comarcas mencionadas, bem como se os direitos humanos foram devidamente respeitados no período definido. METODOLOGIA: Utilizou-se do método Survey que, conforme Mello (20l3), é um método de coleta de informações feitas por questionários para realização da pesquisa. Analisamos os crimes ocorridos em

'Trabalho de Resultado da Pesquisa: DIAGNÓSTICO DOS CRIMES DOLOSOS CONTRA VIDA OCORRIDOS ENTRE OS ANOS DE 2002 A 2006 NAS COMARCAS DE FIGUEIRÓPOLIS, PEIXE E GURUPI-TO, desenvolvida no Programa de Mestrado em Prestação Jurisdicional e Direitos Humanos da UFT 
suas circunscrições para verificar se os órgãos estatais devotaram o mesmo tratamento referente à apuração e processamento e julgamento dos réus, apesar do tamanho e classificação da comarca, e se as investigações sofrem algum prejuízo. RESULTADOS: O levantamento buscou aferir a motivação principal dos crimes dolosos contra a vida, se o comportamento da vítima foi causa determinante para a prática do crime, ou se sua participação foi de somenos para a ocorrência do delito, além da média da idade das vítimas e dos réus, o local onde foi praticado o crime, se público ou privado, o horário predominante, como o fato chegou ao conhecimento das autoridades, se houve ou não prisão cautelar do indiciado-réu e se a vítima e réu tinham algum tipo de relacionamento. CONCLUSÕES: Na área pré-processual (fase administrativa), levantamos dados referentes à atuação da polícia judiciária, analisamos se ela teve o mesmo padrão de investigação nas três comarcas. $\bigcirc$ grau de zelo, empenho, técnicas utilizadas, quantidade de material humano, tempo e resultados na apuração dos homicídios consumados. No caso de divergência entre a atuação dos policiais civis na apuração dos homicídios o que inviabilizou a atuação uniforme nas três comarcas e quais foram as providências necessárias para que tal fato deixasse de acontecer. Em relação à atuação do Ministério Público, verificou-se se este agiu dentro dos prazos legais e se participou ou acompanhou o trabalho da Polícia Judiciária na apuração dos homicídios. Se o Ministério Público, durante a instrução criminal, conseguiu convencer uma sentença condenatória para o réu, se não por quê? Na fase processual, analisamos se efetivamente a ação penal foi desencadeada no ritmo do procedimento tanto no primeiro como no segundo graus. Em caso de condenações, se as penas condenatórias transitadas em julgado tiveram início de execução. Senão, se chegou a uma sentença final, condenatória ou absolutória, o que inviabilizou tal ocorrência? Na fase executória, verificamos as condições dos estabelecimentos prisionais. Concluímos que o tamanho da comarca em nada influenciou na apuração dos fatos, não houve diferença entre a atuação do Ministério Público e a do Poder Judiciário. Muitos fatores devem ter contribuído para o atraso nos processos, mas tais fatores foram difíceis de ser detectados, pois somente uma porção dos processos foi analisada. No entanto, apesar de categorias historicamente vulneráveis (mulheres, negros(as), povos indígenas, idosos(as), pessoas com deficiência, grupos raciais e étnicos, gays, lésbicas, bissexuais, travestis e transexuais, entre outros), denunciarem a violação de direitos, não se tem registro qualificado dessas violações, o que torna urgente e emergente educar em direitos humanos, tarefa indispensável para a defesa, o respeito, a promoção e a valorização desses direitos.

PALAVRAS-CHAVE: Crimes Dolosos, Prestação Jurisdicional, Direitos Humanos.

\section{ABSTRACT}

The intentional crimes against life hurts the most important human right: life. So that there is effectively punishment is necessary for the processing in the administrative phase 
(police investigation) stage and in court (criminal proceedings) should be as quick as possible in order to be given an answer both to the bereaved family and to society, without however neglecting the due criminal process (contradictory, legal defense, legal evidence, natural justice, publicity, impartiality, real truth, equality of the parties, weapons parity, physical identity of the judge, for king). The work results of the Master's research in Constitutional Provision and Human Rights in which elaborate diagnosis of adjudication in the Counties of Figueirópolis, Fish and Gurupi (Ist., 2nd. And 3rd. Indentation respectively) in the period from 2002 to 2006 in the State of Tocantins . GOAL was to diagnose the effectiveness of adjudication in the mentioned counties, as well as human rights were duly respected in the defined period. METHODS: We used the Survey method, as Mello (20 I 3) which is a method of gathering information through questionnaires made to the research. We analyze the crimes in their jurisdictions to verify that state agencies have devoted the same treatment regarding the calculation and processing and trial of the accused, despite the size and classification of the District and investigations suffer some damage. RESULTS: The survey sought to assess the main motivation of crimes against life if the victim's behavior was determinant for committing the offense, or if their participation was of little importance for the occurrence of the offense, beyond the average age of victims and defendants, the place where the crime was committed, whether public or private, the predominant time, like the fact came to the attention of the authorities, whether or not provisional arrest of the accused/defendant and the victim and defendant had some kind relationship. CONCLUSIONS: In the pre-procedural, administrative stage, raise data on the performance of the judicial police, analyze if it had the same standard of investigation in the three counties. The degree of zeal, commitment, techniques used, amount of manpower, time and results in the determination of consummated homicide. In case of divergence between the performance of civilian police in the investigation of homicides what prevented the uniform performance in the three counties and what were the necessary steps so that this fact failed to happen. Regarding the performance of the prosecution if it was the same acted within the legal deadlines and participated in or followed the work of judicial police in the investigation of homicides. If the public prosecutor during the criminal investigation was able to convince a sentence for the defendant, but why?. In procedural stage we analyze effectively the criminal action was triggered, the pace of the procedure both the first and second grades. In case of convictions, whether carried in condemnatory sentences were judged beginning of execution. Otherwise, it came to a final judgment, conviction or acquittal, which prevented such an occurrence. The execution stage, check the conditions of prisons. It concludes that the size of the District at all influenced investigate the facts, there was no difference between the performance of the prosecution, and as the Judiciary, many factors must have contributed to the delay in proceedings, but such factors were difficult to It is detected, since only a portion of the process were analyzed. However, despite historically vulnerable groups (women, blacks (as), indigenous peoples, the elderly (the) people with disabilities, racial and ethnic groups, gays, lesbians, bisexuals, transvestites 
and transsexuals, among others), denounce the violation rights has not qualified record of these violations, which makes it urgent and emerging educate on human rights, an essential task for the defense, respect, promotion and enhancement of these rights.

KEYWORDS: Intentional Crime. Jurisdictional Services. Human Rights.

\section{INTRODUÇÃO}

bem maior que todo ser humano dispõe é a vida. Sem a vida nada importa, pois não se trata mais de pessoa, e sim de coisa, corpo apenas. Ao longo da história da humanidade, desde que o homem se reconheceu como homem, e não como um animal. "O homem é a medida de todas as coisas" (Protágoras).

Assim, sem vida, é desnecessário falar de direitos humanos, pois estes são somente para aqueles que podem dele usufruir.

Para se compreender o que seja homem, devemos fazer uma abordagem em diversos ramos da ciência. Primeiramente, fazer a abordagem filosóficoocidental - que tem como premissa o pensamento grego -, no qual Aristóteles definia que homem é um animal racional, ou seja, um animal que possui razão. A abordagem biológica - ciências naturais -, nela há enorme dificuldade de conceituar "homem", mas para facilitar tal entendimento, a abordagem deve observar a estrutura anatômica e reflexiva. Deve-se levar em conta não somente a estrutura anatômica, mas também tudo o que é suscetível de constatação positiva.

Significa que não basta a conformação anatômica, é necessário considerar a capacidade de pensar, do que pode ser concluído, que o fenômeno humano é original.

Dentro da classificação da taxionomia animal, o homem pertence ao subfilo dos vertebrados, à ordem dos primatas e a uma família firmada por um único gênero, Homo.

Abordagem antropológica - somente após a classificação dos seres vivos, proposta por Lineu e George-Louis Leder Buffon (séc. XVIII), foi possível a integração do homem numa série zoológica e o estudo pelo método de ciências naturais. Uma das contribuições que a antropologia trouxe foi a possibilidade do estudo da herança cultural. $\bigcirc$ homem é portador de cultura, seja pelo domínio da linguagem, seja pelos padrões de organização familiar, o que permite o controle de vasto domínio de conhecimento empírico e pela 
presença de elementos de ordem simbólica, como tabus, mitos, rituais religiosos.

Abordagem psicossociológica - devido à falta de definição entre o relacionamento das dimensões física e cultural do homem, há dúvida quanto ao problema de ser o homem causa ou resultado, criatura ou criador de seu patrimônio cultural. O determinismo ou a liberdade da condição humana é do campo das ciências humanas - Psicologia que traz o conceito psicanalítico de inconsciente. Sigmund Freud mostra que o psiquismo não se reduz ao consciente e somente vencidas certas resistências que alguns conteúdos psíquicos se tornam acessíveis. A sociologia entende que o homem nasce com uma base orgânica que lhe permite desenvolver-se em pessoa. Seu organismo e os sentidos definem o que é efetivamente hereditário, natural e individual, e a vida social e a cultural. O homem vive num círculo permanente de informações que são estímulos diversos e diversamente organizados.

O homem, desta maneira, é um ser essencialmente social, isto é, vive em sociedade, e para que essa convivência seja pacífica e harmoniosa, é preciso que as regras da sociedade sejam respeitadas por todos, o que nem sempre acontece.

As regras de convivência foram estabelecidas pelos membros que compõem o núcleo social, e quando há qualquer infringência a harmonia desaparece.

Como acima explanado, o homem, ser social, ao descumprir qualquer norma imposta a todos igualitariamente, deve ser admoestado para que não incida novamente naquele erro. A admoestação deve ser precedida de um processo que verificará os motivos e consequências. Dependendo do ato, o tempo que poderá ser gasto para se obter uma resposta a todos os envolvidos na situação pode ser demasiadamente longo, fazendo que as pessoas/vítimas desacreditem na justiça. É garantia constitucional que todos têm acesso à jurisdição, contudo, a resposta que a parte e a sociedade esperam deve ter uma duração razoável, levando-se em conta toda a complexidade que envolve os fatos objeto do processo. Deve ser evitado e repudiado qualquer ato processual ou delonga desnecessária que impede o término do processo, mas sempre observando que todo o procedimento deve se pautar pela estrita legalidade, isto é, não pode se afastar em momento algum do devido processo legal.

O bem maior que todos os seres humanos têm é a vida, não há nenhum outro bem mais importante, relevante, pois, sem a vida não há saúde, alegria, tristeza, trabalho, preocupações, o cotidiano. A vida pode se extinguir por diversos modos, naturalmente ou por ação de terceiros ou do próprio detentor 
da vida.

Tal importância foi privilegiada no texto constitucional, tendo sido exaltada como fundamento jurídico e princípio da República, e elevada à categoria de direitos fundamentais com predominância pela dignidade da pessoa humana logo no artigo I , inciso III, que prescreve: "A República Federativa do Brasil, formada pela união indissolúvel dos Estados e Municípios e do Distrito Federal, constitui-se em Estado Democrático de Direito e tem como fundamentos: (...); III - a dignidade da pessoa humana; (...)".

$\bigcirc$ presente texto vem tratar e analisar os homicídios dolosos ocorridos, entre 2002 e 2006, nas comarcas de Figueirópolis, Peixe e Gurupi. Comarcas de $1^{a}$ Instância, mas de entrâncias diferentes, sendo $1^{a}, 2^{a}$ e $3^{a}$, respectivamente.

Nesta análise, será verificado o tempo que levou entre a ocorrência do fato e a resposta final do Poder Judiciário. E durante o trâmite da apuração e processamento quais as causas que impediram o processo de ter um trâmite mais célere. E se foram realizadas perícias técnicas, qual o prazo da conclusão das investigações. A atuação do órgão acusador, em regra o Ministério Público, que detém constitucionalmente a primazia da ação penal, de tentar identificar os motivos e se teve alguma conotação preconceituosa.

Terminada a análise, será apresentada uma proposta para que a atuação das policiais militar e civil, bem como do Poder Judiciário seja mais produtiva, para que a resposta à sociedade e principalmente aos familiares das vítimas de homicídio seja o mais rápido possível.

\section{CRIMES DOLOSOS CONTRAA VIDANO TOCANTINS}

Primeiramente, buscamos informações, no Comando da Polícia Militar, responsável pela área de atuação das comarcas de Figueirópolis, Peixe e Gurupi/TO sobre os homicídios ocorridos nas sedes e distritos judiciários das referidas comarcas entre os anos de 2002 e 2006.

De posse das informações, fomos às Varas Criminais de Figueirópolis e Peixe e à Vara Criminal do Tribunal do Júri e de Execução Penal de Gurupi/TO para levantarmos os inquéritos policiais e, consequentemente, os processos-crimes onde a denúncia tinha como classificação do delito cometido aqueles especificados no artigo 74, $\S 1^{\circ}$, do Código de Processo Penal, ou seja, os crimes dolosos contra a vida, mas apenas os consumados.

Confrontamos as informações da Polícia Militar e os registros dos inquéritos policiais, e a primeira constatação foi que elas não se correspondiam. Diante 
disso, fixamo-nos nos números de inquéritos policiais registrados e depois extraímos apenas os inquéritos policiais que foram instaurados em princípio para apurar um homicídio doloso contra a vida consumado.

Após o levantamento dos inquéritos policiais, fixamo-nos naqueles que efetivamente o Ministério Público ofereceu denúncia, tendo como competência para o julgamento o Tribunal do Júri. No entanto, nem todos foram submetidos ao crivo final do Conselho de Sentença, ou porque o réu fora reconhecido como inimputável, ou porque o processo foi suspenso por não ter sido o réu encontrado para ser citado pessoalmente, ou porque o juiz impronunciou o réu por não vislumbrar indícios de ter sido este o autor do delito, ou não ter prova suficiente da materialidade.

$\mathrm{Na}$ análise dos inquéritos policiais, procuramos verificar se em todas as comarcas, independentemente do tamanho delas, as investigações foram realizadas com a mesma dedicação, principalmente com referência à prova técnica, se os prazos foram respeitados, se não quais os motivos que levaram ao atraso da conclusão das investigações.

Ressalta-se que a comarca de Figueirópolis é de $I^{a}$ Entrância, e além da sede tem apenas o distrito judiciário da cidade de Sucupira. A comarca de Peixe é de $2^{\text {a }}$ Entrância, e além da sede tem três distritos judiciários, as cidades de São Valério, Jaú do Tocantins e o Distrito de Vila Quixaba, pertencentes à cidade de Peixe. E, por último, temos a comarca de Gurupi, que é de $3^{\text {a }}$ Entrância, sendo formada pela sede e quatro distritos judiciários, cidade de Aliança do Tocantins, Cariri, Crixás do Tocantins e Dueré. $\bigcirc$ tamanho das comarcas justifica sua classificação na organização judiciária do Tribunal de Justiça do Tocantins.

$\mathrm{Na}$ fase processual, pesquisamos o sexo dos réus, da vítima, faixa etária, motivos e, principalmente, os prazos para a conclusão das fases processuais, judicium acusationis e o judicium causae.

Com os levantamentos realizados, elaboramos gráficos com os percentuais de processos criminais autuados nas comarcas e quantos desses processos tratavam de homicídios dolosos contra a vida consumados, nos anos da pesquisa (2002, 2003, 2004, 2005 e 2006).

\section{OS CRIMES DOLOSOS CONTRA A VIDA NO DECORRER DA HISTÓRIA BRASILEIRA}

O combate e a força da punição aos crimes dolosos contra a vida têm origem não muito bem definida no decorrer da história, contudo, têm-se notícias de que, desde a Grécia no século IV, a.C., havia júri que era exercido 
pelo Tribunal de Heliastas e formado pelos cidadãos, tendo como local de reunião a praça pública. Têm-se notícias de que, em Esparta, o júri tinha a denominação de Éforos - juízes do povo. Já em Roma, eram denominados quoestiones, posteriormente receberam a denominação de quoestiones perpetuoe, isso porvolta de I 55 a.C.

Na formatação de hoje, referente ao Tribunal do Júri, no Brasil, temos como parâmetro a Carta Magna da Inglaterra, de 1215, na qual havia a seguinte prescrição: "Ninguém poderá ser detido, preso ou despojado de seus bens, costumes e liberdades, senão em virtude de julgamento de seus pares, segundo as leis do país".

Mas antes de ter sua atual formatação, fora aperfeiçoado na França, após a Revolução Francesa, em 1789, com a finalidade de expurgar magistrados umbilicalmente vinculados com a monarquia, passando os julgamentos para um tribunal constituído pelo povo que estava embebido dos novos ideais republicanos.

Curiosamente, a Instituição do Tribunal do Júri fora adotada pelo Brasil antes mesmo de Portugal, que era o nosso colonizador. O Brasil vivia, às vésperas da Independência, um movimento de elaboração de leis que iam contra os interesses da Coroa. Em I 8 de junho de I822, foi criada, no Brasil, a Instituição do Tribunal do Júri pelo Príncipe Regente, por meio de decreto. Sua primeira composição era formada por 24 cidadãos, com o seguinte perfil: "bons, honrados, inteligentes e patriotas", e tinham a competência de julgar os crimes de abuso de liberdade de imprensa, tendo como órgão revisor exclusivamente o Príncipe Regente.

A partir daí o Tribunal do Júri se fez presente na Constituição do Império, de 1824. Já na República, foi criado o Tribunal do Júri Federal pelo Decreto n 848 , de 1890. Permaneceu na Constituição, de 1934, mas fora extirpado na Constituição, de 1937; em 1938 fora confirmado pelo Decreto-Lei n 167 , mas sem a garantia da soberania. Ressalta-se que fora nesse período que ocorreu um dos erros judiciários mais conhecidos, o caso dos irmãos Naves, em Araguari-MG. Na Constituição, de 1946, foi restabelecido o Tribunal do Júri, mantido na Constituição, de 1967, bem como na Emenda Constitucional, de 1969.

Na atual Constituição, nominada Constituição Cidadã, o Tribunal do Júri, como órgão do Poder Judiciário, está previsto no artigo $5^{\circ}$ como um direito e garantia individual, inciso XXXVIII, com competência mínima para o julgamento de crimes dolosos contra a vida e os crimes conexos com ele, visto sua especialidade. Assegura os seguintes princípios: a plenitude de defesa; o sigilo 
das votações; e a soberania dos veredictos.

\section{PANORAMADAS COMARCAS DO TOCANTINS}

Apresentamos o contexto histórico do surgimento das cidades que compõem as comarcas de Figueirópolis, Peixe e Gurupi.

Iniciamos o estudo pela Comarca de I ${ }^{a}$ Entrância, qual seja, Figueirópolis, criada pela Lei Estadual n 238, de 30/I/I99। (DOE 56/91), e instalada em 8/I/I 993. Permaneceu como comarca de I ${ }^{a}$ Entrância na Lei de Organização Judiciária do Tribunal de Justiça do Tocantins n 10/96. Figueirópolis, além da sede, tem apenas o Distrito Judiciário da cidade de Sucupira, e é provida apenas por um juiz de direito.

A cidade-sede teve início nos idos de 1959, quando Cândido dos Santos Figueira fez um loteamento em suas terras as quais denominou "Figueirópolis", mas, nessa época, já vivia na localidade Francisco de Assis Sales (Francisco Felipe) um dos pioneiros na região. Foi Emancipado pela Lei Estadual n 8.848, de 10/6/1980, desmembrado do município de Peixe o distrito de Figueirópolis que é elevado a município. Pelo censo de 2000, Figueirópolis contava com uma população total de 5.562 habitantes, e no Censo de 2010 houve um pequeno decréscimo, com um total de 5.340 habitantes.

$\bigcirc$ único distrito judiciário, a cidade de Sucupira, foi iniciado por volta de 1973, quando Joaquim Alves Queiroz resolveu colocar uma vendinha debaixo de um pé de Sucupira à beira da estrada que ligava o município de Peixe para Figueirópolis usada por fazendeiros para o transporte de gado. Com o tempo, foram chegando famílias e formou-se um pequeno povoado. Pela Lei Estadual n 498, de 20/2/1991, elevado à categoria de município com a denominação de Sucupira. Teve seus limites alterados pela Lei Estadual $n^{\circ} 498$, de 2 1/12/1992, com o desmembramento dos municípios de Peixe e Figueirópolis. Distrito sede instalado em 1\%/1/1993.

Passamos agora à comarca de $2^{\mathrm{a}}$ Entrância, Peixe, a qual tem a cidade com origem mais remota. Peixe é a sede da comarca e leva o mesmo nome.

Antes da criação da comarca de Peixe, a cidade era distrito judiciário da comarca de Porto Nacional.

A comarca foi criada pela Lei no 9.129, de 22/12/1981 (Código de Organização do Estado de Goiás), Anexo I - como Comarca de I Entrância, tendo I Distrito Judiciário - Figueirópolis. Com a criação do Estado do Tocantins, por meio da Medida Provisória n 08, de 1\%/l/ 989 (DOE 0 I/89), 
foi mantida, sendo confirmada Lei Estadual de 23/I/I989 (DOE 04/89) Comarca de I ${ }^{a}$ Entrância. Em 30/I/I 99 I, pela Lei Estadual 238 (DOE 56/9 I) foi alçada de $I^{\mathrm{a}}$ a $2^{\mathrm{a}}$ Entrância, situação que permanece até a presente data. Lei Complementar n 10, de I I/I/1996 (Código de Organização Judiciário do Estado do Tocantins - 2a Entrância. Distritos Judiciários: São Valério, Jaú do Tocantins e Vila Quixaba. Também é provida por um juiz nos termos do art. 25, $\S$ I3, da Lei Estadual n I 0, de I I/I//996.

A origem da cidade de Peixe tem duas versões: a primeira afirma que desde os idos de 1700 havia um porto de passagem de pessoas que vinham de Goiás à procura de jazidas de ouro, principalmente na região hoje da cidade de Natividade-TO. O responsável pelo porto era um lavrador que, além de cultivar sua roça, tinha uma pequena embarcação e fazia a travessia de quem estava em trânsito. Os viajantes constantemente eram atacados por índios denominados "canoeiros" pelos garimpeiros portugueses por serem excelentes remadores, destemidos, inteligentes, também bons cavaleiros, além de serem sanguinários. Os índios canoeiros transitavam entre as cidades de Niquelândia-GO (São José do Tocantins) até Porangatu (Descoberto da Piedade) e tinham verdadeiro ódio pelos "brancos", uma vez que eram perseguidos pelos viajantes.

Em 1767, nasceu Dom João VI, príncipe regente, e os moradores de Natividade mandaram de presente uma pepita de ouro de 45 quilos, a qual tinha o formato de um menino. Em agradecimento ao presente, a mãe de Dom João VI, a rainha Dona Maria I, mandou duas imagens sagradas por seus emissários: Nossa Senhora das Neves e São João Menino, e a informação de que o local onde fora encontrada a pepita de ouro doravante se chamaria Príncipe.

A comitiva encaminhada pela rainha Dona Maria I não chegou ao seu destino porque foram aniquilados pelos índios canoeiros quando passavam pelo porto localizado na hoje cidade de Peixe. Diante dessa tragédia, a Rainha exigiu que o governador geral da Província, além de punir severamente os índios, adotasse medidas para assegurar as caravanas de garimpeiros.

Temos ainda a segunda versão, a qual afirma que, próximo do porto, jesuítas instalaram uma catequese para os índios (canoeiros) da região, o que permitiria seu aldeamento. Havia uma lenda ainda de que havia uma arca escondida que os jesuítas tinham enterrado na localidade do rio Santa Tereza, também conhecida como Arraial das Itans. Em um relatório dos jesuítas estava escrito: "Na mais alta pedra dório Santa Tereza, no lugar denominado itans está sepultado o maior tesouro dos Jesuítas". 
Ambas as versões para o surgimento da cidade de Peixe tem contorno de serem verdadeiras, mas o certo é que, por volta de 1776 e 1780, o alferes Ramos Jubé veio para a região com 25 praças sob o seu comando para garantir a passagem na travessia do rio Tocantins e também para procurar o suposto "tesouro" enterrado pelos jesuítas.

A primeira providência tomada por Ramos Jubé foi determinar a construção de um forte de abobe, aroeira coberto de telha, a fim de evitar os ataques incendiários dos índios. O forte serviu como residência para Ramos Jubé e seus comandados. Consta que o local onde foi construído o forte atualmente é o da residência do Sr. Oscar José da Silva.

Os moradores mais antigos da cidade contam que na referida residência, quando demolida, foram encontradas várias joias, moedas, utensílios de muito valor que estavam dentro de um vaso.

A partir da chegada de Ramos Jubé foi se formando, na beira do porto, um povoado com pessoas oriundas vindas do Carmo, Natividade, Paranã, Conceição do Norte, Porto Nacional, Caititê (BA) e Gilbués (PI).

Temos como os primeiros moradores: Francisco Tavares de Brito e Joaquim Tavares, que foi o primeiro passador do porto.

Ramos Jubé também construiu a primeira casa de oração que ficava na atual praça Getúlio Vargas. A imagem de Nossa Senhora D'Abadia feita pelo santeiro goiano Veiga Vale foi introduzida na igreja antes mesmo de seu término. Histórias são contadas que, após a chegada da imagem de Nossa Senhora D'Abadia, os índios canoeiros nunca mais atacaram o local.

A família do Alferes Ramos Jubé não chegou a vir morar na região, e teve o nome de Santa Cruz das Itans porque ele faleceu antes, vítima de impaludismo.

Após uma grande enchente ocorrida, a rotina dos moradores da região de Santa Cruz das Itans foi alterada, pois uma lagoa que distava a 2 quilômetros das margens do rio Tocantins fora atingida. Quando as águas voltaram ao normal, um peixe enorme ficou preso na referida lagoa e morreu. Dizem que o peixe era tão grande que quatro mulheres batiam a roupa na cabeça dele.

A partir daí, as pessoas que vinham de Vila Boa de Goiás para Natividade diziam: "vamos passar pelo rio onde foi encontrado o peixe", com o tempo só falavam: "passaremos em peixe".

Alguns anos depois passaram a chamar o local de "Vila do Espírito Santo de Peixe", depois de ser promulgada a Lei n ${ }^{\circ} 013$, de 3 I de junho de I846, onde o arraial foi elevado à categoria de município de Palmas (hoje Paranã).

Em 20 de junho de 1895, a vila é elevada à categoria de cidade. Em 31 de dezembro de 1936, Peixe, na divisão territorial de 31 de dezembro de 1936 , 
aparece com o nome de município de Santa Terezinha, sob a jurisdição da comarca de Porto Nacional, mas a população não aceitou referido nome. No Decreto-Lei Estadual n 557, de 3 de março de 1938, no anexo, novamente o município volta à denominação de Peixe.

A primeira lei de que temos notícias é a Lei Provincial n I3, de 30/6/1846Criação do Distrito com a denominação de Peixe, subordinado ao município de Palma. Depois a Lei Estadual n 64, de 20/6/I895, elevou à categoria de Vila com a denominação de Peixe, desmembrado do município de Palma. Sede na antiga vila de Peixe. Temos ainda a Lei Municipal $n^{\circ}$ I, de 26/5/I956, com a criação do distrito de Araguaçu (ex-povoado), subordinado ao município de Peixe.

No censo de 2000, Peixe tinha 8.763 habitantes, e no de 20 I0, houve um acréscimo considerável, tendo sido elevada a população para um total de 10.384 pessoas.

A comarca de Peixe conta com três distritos judiciários, Jaú do Tocantins, São Valério e Distrito de Vila Quixaba. A cidade de Jaú do Tocantins teve início em 1968 quando surgiu a necessidade de transferência da Escola Estadual Cristino Sales localizada nas margens do Rio Almas, arraial de Grafite para outro local, devido à redução de alunos, enquanto em outros locais havia muitas crianças necessitando de estudar. Coube ao professor Justiniano Oliveira Souto encontrar um local de fácil acesso. Após estudar a região, Justiniano escolheu uma mais central, próxima à margem direita do córrego Jaú.

As terras eram de propriedade do Sr. Gesi Alves de Morais, que doou uma gleba de terra para a instalação da escola. Os pais dos alunos interessados em estudar promoveram um mutirão e iniciaram, em 2 de fevereiro de 1969, a construção de um barracão de palha. Enquanto não ficava pronta a escola, ela foi instalada provisoriamente para na Fazenda Cachoeira. No dia 16 de junho de 1969, a escola foi inaugurada, quando era prefeito de Peixe o Sr. Olegário Dias Pinheiro. Muitas famílias passaram a residir em torno da escola para facilitar a frequência das crianças, o que fez surgir um povoamento. A construção de pontes, o desenvolvimento das atividades agropecuárias e o garimpo na região fizeram com que aumentasse a população na localidade. Em 1974, durante o mandato de Wadson Figueira, foi construída uma nova escola municipal, denominada Escola Reunida Pedro Luiz Bonfim, em homenagem a um líder político da região, tendo sido inaugurada no dia 28 de janeiro de 1974.

Em 10 de fevereiro de $|99|$, foi realizado um plebiscito para a emancipação do município, homologado pela Lei Estadual no 251 , de 20 de fevereiro de |99 |, criando o município, cuja instalação se deu no dia $I^{\circ}$ de janeiro de 1993. 
O topônimo de Jaú do Tocantins origina-se do córrego que fica a sua margem com o nome de Jaú.

O município é dividido em sua sede e dos distritos de Povoado Novo Horizonte, Povoado Barrolândia, Povoado Monteirópolis, Povoado Boaventura, Assentamento Beira do Rio, Assentamento Barro Preto e outras áreas rurais.

O município de Jaú do Tocantins foi desmembrado do município de Peixe.

Já o Distrito judiciário de São Valério é a região onde está localizado o município de São Valério, desde os tempos da Coroa Portuguesa, frequentado por pessoas que vinham de Vila Boa de Goiás (Goiás Velho), Cavalcante-GO, em direção ao arraial de São Luiz (Natividade), uma vez que era sede da Ouvidoria Geral da Capitania do Norte. Para se alcançar o arraial de São Luiz (Natividade), passava-se por São João da Palma (Paranã), Porto do Rio Tocantins (cidade de Peixe), rio Manoel Alves (Apinajé), Santa Rosa.

Outro caminho mais ao sul era o que passava por São João da Palma (Paranã), seguia a leste rumo "Contagem do Príncipe", posto de tributação de gado em trânsito de uma capitania para outra e dali para Natividade.

Depois surgiu um caminho mais central saindo de Peixe rumo a Natividade.

Em 197I, à margem direita do Rio São Valério, numa área doada pelo fazendeiro João Sobrinho, foi feita uma construção rústica que serviu de escola para alfabetização das crianças da Fazenda Garroba e redondezas. Este mesmo fazendeiro doou uma área onde fora construída a Capela de Santo Antônio.

A primeira capela foi construída em 1921, denominada Nossa Senhora do Terço, depois Nossa Senhora do Rosário.

E finalmente temos a Comarca de Gurupi, $3^{\text {a }}$ Entrância. Os primeiros habitantes eram os índios xerentes que, em consequência da vinda dos primeiros desbravadores atraídos pela descoberta de cristal, foram se afastando. GURU = diamante PI = puro.

Em 1932, campeando uma tropa de burros que escapara no município de Peixe, Benjamim Rodrigues descobriu um manchão de cristal. Contudo, somente em 1946 é que aportaram na região os primeiros exploradores vindos de Dueré, Porto Nacional e outras regiões do Norte. Fator de suma importância para o desenvolvimento da região fora a construção da BR 14 Belém-Brasília.

Em 9/I0/I 956, pela Lei Municipal $n^{\circ} 251$, foi elevada à categoria de distrito, pertencente a Porto Nacional. Pela Lei Estadual n² 2. I 40, de I 4/I I/I 958, foi elevada a Município. Em 1958, foi emancipado, tendo sido instalado no ano seguinte, $1^{\circ}$ de janeiro de 1959. O censo de 2000 apurou que eram 65.034 
habitantes, e no de 2010 tinha 76.755 pessoas.

Dos distritos judiciários da comarca de Gurupi, cidades de Aliança do Tocantins, Cariri do Tocantins, Crixás do Tocantins e Dueré, o que tem origem mais remota, antes mesmo da sede da comarca é Dueré. A região onde está localizada a cidade de Dueré era habitada pelos índios avá-canoeiros, conhecidos por cara-pretas. Nas proximidades também havia os índios xavantes, os carajás e javaés.

Por volta de 1948, um grupo de amigos liderados por Benedito Leopoldino da Fonseca, conhecido por Tenente Fonseca, saiu do Distrito de Chapada (Cristalândia) rumo ao sul à procura de jazidas de cristais de rocha e chegaram aonde hoje é a cidade de Dueré.

Os índios avá-canoeiros eram arredios e provocaram muitas lutas com os garimpeiros e com os primeiros fazendeiros que se estabeleceram na localidade.

As demais etnias primeiramente também não eram amigáveis aos garimpeiros, mas, devido ao grande número, passaram a conviver pacificamente com eles, contudo sem se envolverem no trabalho. Depois foram descobertas novas jazidas denominadas Fio Azul e Monchão do Simeão, o que atraiu muitas pessoas, formando assim o povoado.

Em 1953, pela Lei Municipal n 2. I 88, de I0/I I/I953, a Câmara Municipal de Cristalândia elevou o povoado à categoria de Distrito, com a denominação de Dueré, devido à proximidade com o rio Dueré, afluente do rio Araguaia.

A Lei Estadual n².119, de 14/1 I/1958, elevou o distrito à categoria de município, com a denominação de Dueré, instalado em $1^{\circ}$ de janeiro de 1959.

Foi desmembrado do município de Cristalândia e é constituído do distritosede.

Os demais municípios tiveram como principal fonte de desenvolvimento a construção da BR Belém-Brasilia por volta dos anos de 1970.

\section{LEVANTAMENTO DOS HOMICÍDIOS CONSUMADOS OCORRIDOS NAS COMARCAS NO PERÍODO DE 2002 A 2006}

Após levantamentos nas escrivanias criminais das comarcas, primeiramente foi levantado o número de efeitos criminais autuados no período de 2002 a 2006. Na comarca de Figueirópolis foram autuados, nesse período, 502 processos, nenhum deles referente a homicídios consumados.

Na comarca de Peixe, tivemos 275 processos criminais autuados, destes, 7 se referem a homicídios dolosos consumados, o que dá uma porcentagem de 2,55\% dos crimes ocorridos na comarca. 
E na comarca de Gurupi, foram autuados, no período de 2002 a 2006, somando as autuações registradas nas três escrivanias criminais, 1.459 processos. Destes, 16 foram de homicídio doloso consumado o que perfaz $1,10 \%$ dos processos registrados no período.

A primeira conclusão possível de se chegar é a de que, apesar de ser uma comarca muito menor em relação às demais, Figueirópolis teve mais processos criminais autuados do que a comarca de Peixe, mas, em compensação, nenhum deles referente a homicídio doloso consumado.

A segunda conclusão é a de que a proporção de homicídios dolosos contra a vida no período foi maior na comarca de Peixe, que é de $2^{\mathrm{a}}$ Entrância e relativamente menor do que a comarca de Gurupi, caso se considere a população total da comarca.

Referente à atuação da Polícia Militar, em muito ficou prejudicada a pesquisa, visto que não é comum fazer juntada do Boletim de Ocorrência elaborado pela referida instituição. Em regra, é a polícia militar que chega aos locais de crimes e aciona a polícia civil. Em todos os atendimentos, a polícia militar elabora um boletim de ocorrência. Ocorre que não é costume de os policiais militares entregarem uma cópia do referido boletim na Delegacia de Polícia para que seja juntado aos autos. Tal situação deixa as estatísticas policiais subdimensionadas. Nos delitos que não demandam a intervenção imediata da polícia civil, muitos deles não chegam ao conhecimento da autoridade policial, pois as vítimas acionam a polícia militar e são orientadas a procurar depois uma unidade da polícia civil para registrar a ocorrência, o que muitas vezes as vítimas não fazem, ou por falta de tempo ou por não acreditarem que o problema será resolvido, principalmente nos casos de delitos de menor potencial ofensivo.

Quanto aos prazos para a conclusão do procedimento na fase administrativa, alguns extrapolaram em muito, chegando a ponto de um dos processos ter levado 7 anos para sua conclusão. Mas, referente aos procedimentos periciais, nenhuma diferença fora notada em decorrência do tamanho da comarca, pois em todos eles houve as perícias técnicas comuns (local de crime, necropsia).

A atuação do Ministério Público em todos os processos não merece destaque, uma vez que cumpridos os prazos consoante determinados na lei.

A média do processamento dos feitos na fase judicial é muito diversificada em todas as duas comarcas, pois não foi possível estabelecer um padrão de conclusão. A média girou em torno de 2 anos para os processos que não tiveram recursos nas suas fases. Mas destaca-se haver processo ainda tramitando, transcorridos II anos. Trata-se de um processo que teve recursos 
em todas as fases processuais e está com agravo de instrumento pelo não recebimento do Recurso Especial.

Não foi detectado nenhum crime com motivação sexual, de raça ou que possa ser incluído nos chamados crimes de motivação de minorias. Os motivos não são muito claros nesse tipo de processo, pois, em plenário, pela garantia constitucional da ampla defesa, pode alegar qualquer fato que julgue relevante para a absolvição do seu cliente, não estando adstrito a questões enumeradas legalmente. Mas bebidas e discussões sem grande relevância podem ser identificadas como princípio ou detonador dos fatos.

Os autores, todos foram homens, com instrução mediana (uma vez que afirmaram ser alfabetizados), e as vítimas, com exceção de uma delas, também foram homens. A média de idade gira em torno de trinta e poucos anos.

Dentre os processos instaurados na comarca de Peixe, 4 réus foram condenados, 2 receberam absolvição imprópria com imposição de medida de segurança e I encontra-se em curso.

$\mathrm{Na}$ comarca de Gurupi, um réu foi impronunciado, um absolvido com imposição de medida de segurança, onze condenados, dois processos suspensos nos termos do artigo 366 do CPP e um processo não foi localizado.

\section{CONCLUSÕES}

O tamanho da comarca em nada influenciou a apuração dos fatos pela polícia judiciária, considerando-se os trabalhos periciais. Em todos os processos envolvendo homicídio doloso consumado, foram realizadas as perícias necessárias para a persecução criminal. O que pode ser observado é que, na comarca de Gurupi, alguns inquéritos foram concluídos com maior atraso que na comarca de Peixe, podendo ser um dos fatores ao atraso nas diligências o número expressivo de delitos ocorridos na comarca de Gurupi em relação aos que aconteceram na comarca de Peixe.

Ressaltamos não ter havido diferença entre a atuação do Ministério Público nas duas comarcas, os prazos impostos foram cumpridos conforme determina a lei.

Referente ao Poder Judiciário, muitos fatores devem ter contribuído para o atraso nos processos, mas tais fatores foram difíceis de serem detectados, uma vez que somente uma porção dos processos foi analisada. Para estabelecer o fator ou fatores que contribuíram para que a família da vítima e a sociedade recebessem a resposta do crime pelo qual se submeteram, necessário fazer um diagnóstico em todos os setores que estão envolvidos na Comarca a ser 
pesquisada.

Mas um dos problemas que não mais ocorrerá, será o possível sumiço de processo ou inquérito, já que todos os processos e inquéritos policiais são eletrônicos.

Necessário seja feita uma intervenção urgente na postura da polícia militar e polícia civil para que trabalhem em conjunto e harmonicamente, a fim de evitar sejam subdimensionadas as estatísticas da criminalidade. Uma das sugestões é a de que uma cópia de todos os boletins de ocorrência, elaborada pela Polícia Militar em atendimento a qualquer ocorrência policial, seja encaminhada à polícia civil para que a autoridade policial analise se é caso, ou não, de se instaurar o competente inquérito policial.

Também necessário seja aumentado o número de policiais civis, nas unidades policiais, para que concluam as investigações com maior agilidade e rapidez, isso no sistema de segurança pública.

No âmbito do Poder Judiciário, necessário seja identificado o gargalo que está impedindo o trâmite dos processos com maior rapidez. Se é por que efetivamente o réu e seu advogado estão protelando a conclusão do procedimento ou se a causa é afeta a alguma falha estrutural do Poder Judiciário.

Finalmente, no que se refere às categorias historicamente vulneráveis (mulheres, negros(as), povos indígenas, idosos(as), pessoas com deficiência, grupos raciais e étnicos, gays, lésbicas, bissexuais, travestis e transexuais, entre outros), se denunciarem a violação de direitos, não se terá registro qualificado dessas violações, o que torna urgente e emergente educar em direitos humanos, tarefa indispensável para a defesa, ao respeito, à promoção e à valorização desses direitos.

Vivemos todos nós um momento social crítico, de certo acirramento entre as forças fundamentalistas e os ativistas na luta pelos direitos fundamentais. Cada vez mais se observam medidas de violência contra grupos vulneráveis no próprio espaço institucional e político partidário. $\bigcirc$ fundamentalismo existe justamente quando um grupo pretende que os princípios de sua fé sejam generalizados para a toda a sociedade, via Lei, opondo-se à concepção de democracia.

De outro modo, no momento em que a garantia dos direitos humanos violados precisam ser judicializados, sinaliza-nos a inoperância das políticas públicas de Estado e a neutralidade de políticos de vocação conservadora na grande bacia de Pilatos. 


\section{REFERÊNCIAS}

BEDAQUE, Jose Roberto dos Santos. Direito e processo: influência do direito material sobre o processo. $3^{\mathrm{a}}$ ed. São Paulo: Malheiros, 2003.

Malheiros, 2006.

Efetividade do processo e técnica processual. São Paulo:

CHOUKR, Fauzi Hassan. Garantias constitucionais na investigação criminal. $3^{\mathrm{a}}$ ed. Rio de Janeiro: Lumen Juris Editora, 2006.

Juris, 2002.

Processo Penal de Emergência. Rio de Janeiro: Editora Lumen

. A Convenção Americana dos Direitos Humanos e o Direito

Interno Brasileiro - bases para sua compreensão. São Paulo: EDIPRO Edições Profissionais, 2001 .

Processo Penal à Luz da Constituição - temas escolhidos. Bauru: EDIPRO - Edições Profissionais, 1999.

FERRAZ, Anna Cândida da Cunha (Org.); BITTAR, Eduardo Carlos Bianca (Org.). Direitos Humanos Fundamentais: positivação e concretização. I ${ }^{a}$ ed. Osasco-SP: Edifieo, 2007.

MELLO, Carlos (Org.). Métodos quantitativos: pesquisa, levantamento ou survey. Aula 09 da disciplina de metodologia de pesquisa na UNIFEI. Disponível em: <http://www.carlosmello.unifei.edu.br/Disciplinas/Mestrado/PCMI 0/Slides-Mestrado/Metodologia_Pesquisa_2012Slide_Aula_9_Mestrado.pdf $>$. Acesso em 20 out. 2013.

MIRANDA COUTINHO, Jacinto Nelson de; CASTANHO DE CARVALHO, Luis Gustavo Grandinetti (orgs). O Novo Processo Penal à Luz da Constituição. Rio de Janeiro: Lumen Juris, 2010.

MORAIS DA ROSA, Alexandre. CARVALHO, Thiago Fabres de. Processo Penal Eficiente e Ética da Vingança. Rio de Janeiro: Lumen Juris, 20 I 0.

ZAFFARONI, Eugenio Raul. O inimigo no Direito Penal. Trad. Sérgio 
Lamarão. Rio de Janeiro: Revan, 2007.

SILVA SÁNCHEZ, Jesús-Maria. Eficiência e direito penal. Trad. Mauricio Antonio Ribeiro Lopes. Barueri: Manole, 2004.

THEODORO JÚNIOR, Humberto. Direito e processo: aprimoramento e modernização do direito processual. Rio de Janeiro: AIDE, 1997 


\section{ANEXOS: DADOS POR COMARCA}

Figueirópolis: Processos-Crimes Autuados nos Anos:

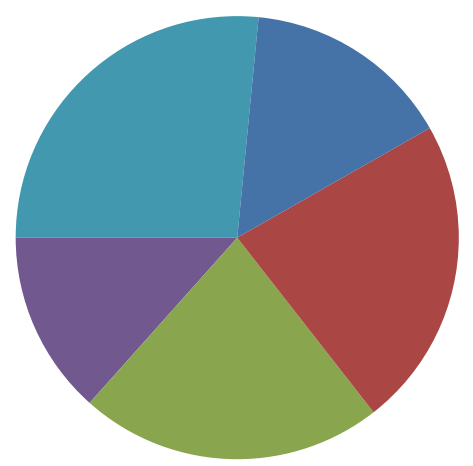
2002: $83=0,0 \%$
$2003: 94=0,0 \%$
$2004:|0|=0,0 \%$
$2005: 90=0,0 \%$
2006: $134=0,0 \%$
Total Geral $502=0,0 \%$

Nenhum dos feitos refere-se a homicídio doloso consumado

Comarca de $2^{\text {a }}$ Entrância de Peixe-TO

Processos-crimes autuados nos Anos

\begin{tabular}{|c|c|c|}
\hline Ano & Processos & \% homicídio doloso consumado 2002-2006 \\
\hline 2003 & 41 processos & $2,44 \%$ \\
\hline 2004 & 25 processos & $8 \%$ \\
\hline 2004 & 64 processos & $3,13 \%$ \\
\hline 2005 & 69 processos & $1,45 \%$ \\
\hline 2006 & 76 processos & $1,32 \%$ \\
\hline Total Geral: 275 & 41 processos & $2,55 \%$ \\
\hline
\end{tabular}

Peixe: Processos-Crimes Autuados nos Anos:

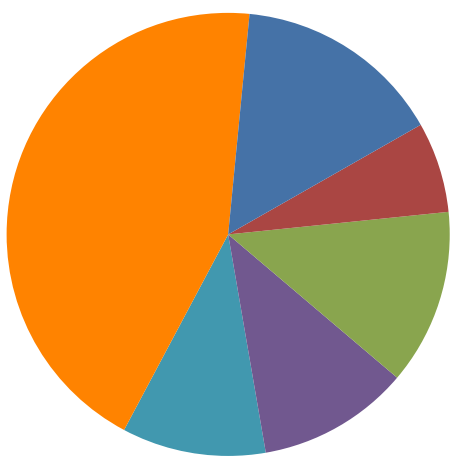

$2002: 41=2,44 \%$

$2003: 25=8 \%$

$2004: 64=3,13 \%$

$2005: 64=3,13 \%$

$2006: 76=1,32 \%$

Processos criminais autuados no período: 275

Total Geral $275=2,55 \%$ 


\section{Comarca de $3^{\mathrm{a}}$ Entrância de Gurupi-TO}

Processos-crimes autuados nos Anos:

\begin{tabular}{|c|c|c|c|c|c|}
\hline Ano & $\begin{array}{l}I^{a} \vee . \text { Criminal } \\
\text { (proc) }\end{array}$ & $\begin{array}{l}2^{a} \vee \cdot \text { Criminal } \\
\text { (proc) }\end{array}$ & $\begin{array}{l}\text { Ex. Penal } \\
\text { Tribunal Júri }\end{array}$ & $\begin{array}{l}\text { Total de } \\
\text { Processos }\end{array}$ & $\begin{array}{l}\text { \% Hom. } \\
\text { consumados }\end{array}$ \\
\hline 2002 & 98 & 88 & 24 & 210 & $1,43 \%$ \\
\hline 2003 & 88 & 123 & 19 & 230 & $1,30 \%$ \\
\hline 2004 & 97 & 75 & 26 & 198 & $2,53 \%$ \\
\hline 2005 & 115 & 127 & 17 & 400 & $0,5 \%$ \\
\hline 2006 & 206 & 162 & 53 & 421 & $0,71 \%$ \\
\hline Total Geral & 1.459 & & & & $1,10 \%$ \\
\hline
\end{tabular}

\section{Gurupi: Processos-Crimes Autuados nos Anos:}

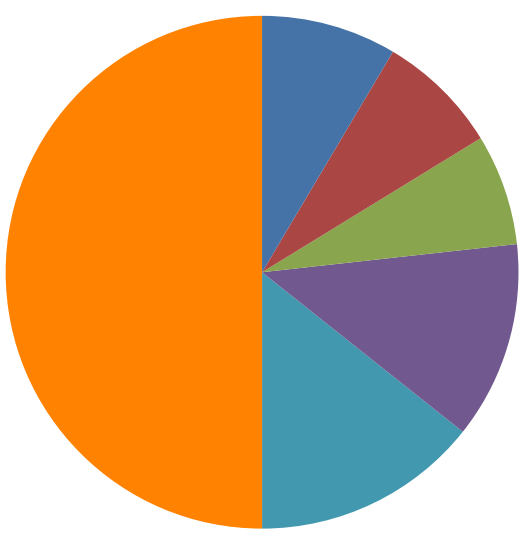

2002: I ${ }^{\mathrm{a}}$ V. Crim 98;2 V. Crim 88;Exec.P/T. úri 24 ; Total: $210=1,43 \%$

2003: | ${ }^{\mathrm{a}}$ V. Crim 88;2a V. Crim

I23;Exec.P/T. Júri 19; Total: $230=1,30 \%$

2004: I ${ }^{\mathrm{a}}$ V. Crim 97; $2^{\mathrm{a}}$ V. Crim 75;Exec.P/T. úri 26 ; Total: $198=2,53 \%$

2005: | ${ }^{\mathrm{a}}$ V. Crim I 15;2 ${ }^{\mathrm{a}} \mathrm{V}$. Crim

127;Exec.P/T. Júri 17;Total: $400=0,5 \%$

2006: | ${ }^{\mathrm{a}}$ V. Crim 206;2 ${ }^{\mathrm{a}}$ V. Crim

|62;Exec.P/T. Júri 53;Total: 42 | = 0,7|\%

Total Geral: $1.459=1,10 \%$

Recebido em: 28/06/2015

Aprovado em: 14/01/2016 
